\title{
Empowerment of Home Health Care Case Managers
}

\section{${ }^{1 *}$ Linda Basso Melodia, DNP, RN, ${ }^{2}$ Barbara Penprase, PhD, RN,}

\section{${ }^{3}$ Linda L. Strong, EdD, RN}

${ }^{1 *}$ Adjunct Assistant Professor and Advisor for Geriatric Health and Wellness, Sacred Heart University College of Nursing, Fairfield, CT

${ }^{2}$ Professor, Oakland University

${ }^{3}$ Director RN-BSN/MSN Program, Sacred Heart University College of Nursing, Fairfield, CT. melodial@sacredheart.edu

\begin{abstract}
Background: Job satisfaction and feelings of empowerment positively impact home health care nurses by improving patient safety and patient outcomes. The project objective determined whether an empowerment educational module improved the feelings of empowerment and job satisfaction of registered nurses at a home health care agency.
\end{abstract}

Methods: A quantitative, pre-test/post-test research study was conducted to measure the success of an empowerment educational module. Laschinger's (2008) Nursing Worklife questionnaire was administered to 92 participating nurses, 46 were assigned to an experimental group and 46 were assigned to a control group. Participants in the experimental group were queried about their perceptions towards empowerment in home health care environments and their reactions towards the teaching module.

Results: The educational module did not significantly impact the participants' sense of empowerment and seemed to weaken the empowerment at times, albeit in statistically insignificant numbers. Six themes emerged from this discussion.

\section{INTRODUCTION}

Home health care is one of the fastest-growing segments of the American health sector. Between 2010 and 2014, the U.S. Department of Labor projects an increase of nearly 90,000 jobs in the field (Bureau of Labor Statistics, 2015). While several disciplines are involved in the delivery of care, registered nurses provide the greatest amount of hands-on work. According to Bercovitz and Feldman (2011), more than 27 million older adults will require community-based, long-term care by 2050. These figures suggest that more nurses will continue to enter homecare.

Home health care is perceived as a highly independent vocation, as nurses' work in patients' homes while a central office provides administrative and support services (Ellenbecker, Samia, Cushman and Alster, 2008). A few of the many duties of a homecare nurse includes conducting assessments, discerning issues that place the patient in jeopardy, initiating contact with the physician and making changes to the patients' care plan. Homecare nurses are perceived as more independent than traditional nurses, as they are given the opportunity to make critical decisions regarding patients' care (Harris, 2015). Due to the gravity of their role as care providers, it is imperative that nurses are personally prepared and environmentally supported by their workplace to tackle the responsibilities of the position. It is questionable as to the extent that this responsibility is actually fostered in the workplace, as well as their perceptions towards control of this practice.

In an effort to improve the feelings of empowerment and the job satisfaction of homecare nurses, this projectused a pre-posttest design to test the successes of an empowerment educational module for homecare nurses. The 


\section{Empowerment of Home Health Care Case Managers}

objective was to determine the effect of an educational module on the nurses' sense of empowerment. The population of this project consisted of registered nurses working in homecare in a nonprofit, home health care agency located in a New England state in the United States. The sample was comprised of 92 participants: 72.8 percent were between the ages of 34 and 58, 93.5 percent female and 6.5 percent male.

The results of this project were not definitive and demonstrated small decreases (albeit statistically insignificant) in empowerment following the intervention of the empowerment educational module. This suggested the need for further research on the subject matter.

\section{LITERATURE REVIEW}

Home health care primarily functions through services conducted by homecare nurses (Harris-Kojetin, Sengupta, Park-Lee and Valverde, 2013). Compared with other health care vocations, the relationship between nurses and physicians requires less direct communication, though physicians are highly dependent on the nurses' assessments of the patients' care plans (Ellenbecker et al., 2008). These nurses accommodate various care requirements directly correlated with a patient's standard of living and how it affects their treatment. Among the patients availing homecare services, approximately 86 percent are age 64 and older, while 83.2 percent have three or more chronic conditions (Visiting Nurse Associations of America, 2015). Of these patients, 65 percent have an annual income that is 200 percent below the Federal Poverty Level, 36 percent live alone and 29 percent have major functional limitations (Avalere Health, 2015). New or worsening symptoms of patients must be recognized, immediately reported and remedied by homecare nurses.

\section{THE EFFECTS OF EMPOWERMENT ON HoMECARE NURSES}

The empowerment of nurses is particularly vital to patient safety, the work climate and the autonomous practice environments that foster innovation in a clinical setting (Armstrong, Laschinger and Wong, 2006). Hence, empowered nurses are more valuable to the health care setting, as they increase the quality of patient care (Laschinger, 2008). The nurses' job satisfaction, commitment and productivity is positively impacted by feelings of empowerment (Ellenbecker et al., 2008). Laschinger's (2008) Nursing Worklife Model examines the impact of empowerment on professional work environment factors that led to nursing satisfaction. Empowerment is a means for nurses to become more satisfied with their job, while simultaneously improving the quality of patient care (Laschinger, 2008). Therefore, the significance of fostering the sense of empowerment of staff in the homecare setting cannot be overstated.

According to prior studies, nurses theorize empowerment as having the autonomy to make judgments in the practice setting (Rao, 2012; Trus, Razbadauskas, Doran and Suominen, 2012). This power is fostered through the interaction between the nurses and patients, and the nurses and the care providers. The ideal qualities of an empowered nurse includes, "moral principles, expertise, personal integrity, future orientation and sociability" (Trus et al., 2012, p. 417). According to Manojlovich (2007), an empowered nurse has the knowledge and expertise to ensure that his or her skill sets are consistently updated (Manojlovich, 2007). Using mixed methods approach, Williamson (2007) collected quantitative data using the Psychological Empowerment Instrument, and qualitative data collected from interviews and observationsof 15 homecare nurses regarding empowerment and its influence on the nurses' decisions. Results described an empowered homecare nurse as "independent, confident, trusting and comfortable with providing quality care" (Williamson, 2007, p. 140). The majority of homecare nurses perceived empowerment as having choices in the workplace as well as a sense of meaning and competency in what they do (Williamson, 2007, p. 140).

\section{Structural Empowerment in Nursing Practice}

The structure of opportunity is created through a workplace climate where individuals are encouraged and able to expand their skill set and knowledge bases. Employees encouragedto advance in the workplace are overall 


\section{Empowerment of Home Health Care Case Managers}

more motivated than employees who are not (Kanter, 1993b). In a meta-analysis study, Davies et al. (2011) examined 17 studies consisting of 10 quantitative studies, four qualitative studies, two process evaluations and a mixed methods study. Davies et al. (2011) found that structure of power in the workplace is facilitated from three primary sources : "(a) right to use information, (b) right to access support and (c) right to use the resources required for realizing organizational goals" (p. 1). The presence of these three sources begins with a balance between the workplace itself and its leadership.

\section{CONCEPTUAL FRAMEWORK AND EMPOWERMENT INSTRUMENT}

The conceptual framework that guided this project was based on two theories. First, the Structural Theory of Organizational Empowerment (Kanter,1993a), outlined attitude and behaviors in the workplace and the notion that perceived access to power and opportunity structures affects the behaviors and attitudes of employees. Kanter (1993a) suggested that individuals display different behaviors and attitudes depending on whether certain structural supports (power and opportunity) are in place. Second, Laschinger's (2008) Nursing Worklife Model explains how work environment characteristics affect nursing practice contributing to or mitigate burnout. The Nursing Worklife Model makes use of the constructivist approach in which it contextualizes a process of constructing knowledge rather than acquiring it.

The empowerment educational module under construction teaches nurses about the significance of empowerment as well as methods on how to empower. The effectiveness of the educational module was examined through a quantitative, pre-test/post-test design, where the nurses' sense of empowerment was measured using the Conditions for Work Effectiveness Questionnaire II (CWEQ-II) (Laschinger, Finegan, Shamian and Wilk, 2001). The six dimensions of empowerment of the CWEQ-II are the following: access to opportunity, access to resources, access to information, access to support and formal power and informal power (Laschinger et al., 2001).

\section{PURPose OF PRoject}

The purpose of this doctoral project is to improve the case mangers' sense of empowerment in the workplace setting through the completion of an educational module related to empowerment through learning, and obtain their perceptions towards the homecare work environment.

\section{METHODS}

Using a pre-test/post-test design this doctoral project was conducted in a nonprofit home health care agency located in a New England state that provided 1.4 million residents in 52 communities with care throughout the year 2013. A total of 143 accredited nurses who function in a variety of roles and titles staff the homecare agency. A total of 92 nurses were eligible for participation in this project, of which 46 were randomly assigned to an experimental group and 46 were randomly assigned to a control group. All participants completed the demographic survey and the CWEQ-II for the pre-test exactly one week prior to the first session interview. Participants who were assigned to the experimental group participated in two one-hour session modules; the first of which occurred a week after the pre-test in which strategies were discussed concerning personal and professional empowerment. The experimental group attended one session per week for two consecutive weeks, while the control group carried on with their regular activities. At the conclusion of the experimental group's third session of the educational module, a post-test using the CWEQ-II was administered to both the control and experimental groups to measure change in the participants' sense of empowerment.In this pre-test/post-test quantitative project, numerical data (i.e. pre-test/post-test scores) were collected by administering the CWEQII. The module included topics about better understanding the concept of empowerment and methods that empower homecare nurses in the workplace setting. The type of data collected was specified prior to the study (Creswell, 2009) and the researcher interpreted the statistical results. Changes in the scores from the pre-test were analyzed to identify differences between the control and experimental groups. 


\section{Empowerment of Home Health Care Case Managers}

To elicit perceptions towards the empowerment sessions participants of the experimental groups were queried by the researcher at the conclusion of the second educational session. Responses were recorded, reviewed, analyzed for common concepts and then organized into exemplars. A second reader reviewed the responses, consensus was achieved between concepts, themes and exemplars.

\section{FINDINGS}

Analysis demonstrated that all of the study variables satisfied the assumption of equality of variances, which included opportunity ( $p=.97)$, information $(p=.84)$, support $(p=.95)$, resources $(p=.48)$, formal power $(p$ $=.35$ ) and informal power $(p=.09)$ (Table 1). The mean difference between the pre-test/post-test scores was computed and descriptive statistics were used to assess if the mean score for each dimension on the CWEQ-II improved the nurses' sense of empowerment after receiving the intervention module. Aside from the resources and informal power results, all of the other dimensions in question demonstrated a mean decrease for both the experimental and control groups (Table 2). The results of the mixed ANOVA showed there was a decrease in the nurses' sense of empowerment for opportunity, information, support and formal power, however, the resources and informal power dimensions showed a mean increase for the experimental group.

To assess the nurses' sense of access to opportunity, resources, information, support and formal and informal power, a Spearman's rho correlation coefficient calculator was utilized and found that a statistically small, positive association exists between education and support. The results indicated that while most of the test scores reflected a negative change in scores, this was not statistically significant for opportunity $(p=.88)$, information $(p=100)$, support $(p=.62)$, resources $(p=.74)$, formal power $(p=.91)$ and informal power $(p=$ .73). The findings were not statistically significant, therefore the null hypothesis was not rejected. This suggests that there was no difference the nurses' sense of empowerment after receiving the empowerment education module.

The participants of the experimental group expressed a range of emotions towards the power to control, influence, affect change or manage the current homecare work environment. More than 47 comments were collected, aggregated and reviewed for common themes. Participants in three out of the four branch offices were consistent in the types of themes and concerns raised while the fourth branch conveyed a more positive perception. The following exemplars were common among four of the participating branches and produced six themes.

Table 1: Tabulation of Exemplars and Corresponding Themes

\begin{tabular}{|l|l|}
\hline Exemplars & Themes \\
\hline $\begin{array}{l}\text { I need more communication } \\
\text { Lack of communication } \\
\text { Administration not listening, they smile and say “I hear you" but } \\
\text { will not do anything } \\
\text { We are not being heard } \\
\text { I am so frustrated by the lack of communication }\end{array}$ & \\
\hline $\begin{array}{l}\text { No job satisfaction, } \\
\text { I am making mistakes } \\
\text { because of the workload, } \\
\text { I am not able to work as a nurse } \\
\text { I just work and take my work home with me }\end{array}$ & $\begin{array}{l}\text { Let me be the nurse that I can be, that I used } \\
\text { to be, that I strive to be! }\end{array}$ \\
\hline
\end{tabular}


Empowerment of Home Health Care Case Managers

\begin{tabular}{|c|c|}
\hline $\begin{array}{l}\text { I am making mistakes } \\
\text { because of the workload } \\
\text { My patients become angry because they are being seen by many } \\
\text { other staff } \\
\text { I have no control over my } \\
\text { practice, } \\
\text { I am just a visit machine } \\
\text { The nursing supervisors are the case managers. } \\
\text { I felt less empowered after because I now know how much I } \\
\text { didn't } \\
\text { know and I began to look at myself differently } \\
\text { It wasn't like this } 14 \text { years ago } \\
\text { We can't keep new staff because of overwhelming caseloads } \\
\text { (50-60-70) } \\
\text { Unsafe practice, need to lower the census } \\
\text { I am empowered, very supported by the environment (census } \\
30-35 \text { ) }\end{array}$ & $\begin{array}{l}\text { It's the patient's that are our priority how can } \\
\text { I have a safe practice with so many patients, } \\
\text { so many demands? }\end{array}$ \\
\hline $\begin{array}{l}\text { I have no life, } \\
\text { I just work and take my work home with me } \\
\text { Have a great work balance }\end{array}$ & Work follows me home... \\
\hline $\begin{array}{l}\text { I felt so good after session one and so empowered } \\
\text { We don't hear about the good stuff Always hear about prob- } \\
\text { lems } \\
\text { Can't feel empowered with this much work } \\
\text { Supportive environment }\end{array}$ & $\begin{array}{l}\text { I feel like crying even when I should be happy } \\
\text { and satisfied with my work. }\end{array}$ \\
\hline $\begin{array}{l}\text { I ended up so frustrated I ended up crying } \\
\text { Other homecare agencies have more staff that can do the cleri- } \\
\text { cal work and the RNs can be out in the field } \\
\text { I am so frustrated by the lack of communication }\end{array}$ & The problems seem insurmountable ... \\
\hline
\end{tabular}

\section{DisCUSSION}

For both the experimental and control groups, all of the elements measuring nurses' sense of empowerment showed a mean decrease, except for the resources and informal power measures. Despite these mostly negative changes in test scores after receiving the empowerment education module, the changes were statistically insignificant for the opportunity, information, support, resources, formal power or informal power measurements. This lack of statistical significance suggested that the empowerment education module had little to no effect on sense of empowerment. The data demonstrated a statistically insignificant decrease in the dimensions of opportunity, information, support and formal power. In contrast, the data for resources and informal power demonstrated a mean increase. Additionally, the following dimensions trended toward statistical significance: education and information, education and formal power and gender and formal power. The project was based heavily in previous research, a lack of statistical significance occurred for many variables, which made definitive conclusions challenging (Dall et al., 2013; Lynch, 2015; Royer, 2011). The decrease of 
many dimensional statistics post educational module showed the social constructivist nature of empowerment. Possibly, the rather unexpectedly underwhelming impact of the empowerment educational module was the result of a disparity between the researcher's and the nurses' concept of empowerment.

The qualitative portion of this project illuminated the reality that a many nurses felt powerless and are overworked. This is a troubling sign when considering that these nurses remain important to the home-healthcare sector (Dall et al., 2013). The literature review demonstrated that home-healthcare nurses act more like clinicians than nurses, as they transfer treatments and information communicated from a central office (Cowen \& Moorhead, 2014). Due to their importance to the sector and their increased responsibilities when compared to non-home-healthcare nurses, their empowerment is not only essential to their personal success, but also to the health of their patients (Cowen \& Moorhead, 2014; Wong \& Laschinger, 2013).

\section{CONCLUSIONS}

This project used a quantitative design to determine the effectiveness of an empowerment education module on homecare nurses. The qualitative responses illuminated the reality that many nurses felt powerless and overworked in their profession. This study used previous research to develop a new model of structural empowerment for homecare nurses. Findings of this project were not dramatic or conclusive. While certain statistically significant results exist, those that were statistically significant were only weakly so. In short, the nurse empowerment educational module did not have a significant impact on the participants' sense of empowerment and, in fact, seemed to weaken the empowerment at times, albeit in statistically insignificant numbers. One of the most illuminating portions of the study was the qualitative section. Several common themes were collected, which provided a window into the general morale of home-healthcare nurses at this agency.Although the basis of this research was to build and improve upon previous research, the lack of statistical significance remains notable, given the wealth of research on empowerment theory and structural empowerment. Recommendations for further investigation include, replication with a larger sample that is more diverse in the specialties of nursing home health care,comparison of large and small agencies, and comparison of rural to urban-suburban agencies.

\section{REFERENCES}

Alenius, L., Tishelman C., Runesdotter, S., \& Lindqvist, R. (2013). Staffing and resource adequacy strongly related to RNs' assessment of patient safety: a national study of RNs working in acute-care hospitals in Sweden. BMJ Qual Saf. 23(3), 242. doi:10.1136/bmjqs-2012-001734.

Armstrong, K., Laschinger, H. K. S., \& Wong, C. (2009). Workplace empowerment and magnet hospital characteristics as predictors of patient safety climate. Journal of Nursing Care Quality, 24(1) 55-62. doi: 10.1097/NCQ.0b013e31818f5506

Avalere Health (2015). Home health chartbook: Updated data and trends for home health care in the United States, 2015. Retrieved from http://www.ahhqi.org/research/home-health-chartbook.

Bercovitz, J., \& Feldman, M. (2011). The mechanisms of collaboration in inventive teams: Composition, social networks, and geography. Research Policy, 40(1), 81-93. http://dx.doi.org/10.1016/j.respol.2010.09.008

Bureau of Labor Statistics (2015). Home Health Aides. United States Department of Labor. Retrived from http:// www.bls.gov/ooh/healthcare/home-health-aides.htm

Cowen, P. S., \& Moorhead, S. (2014). Current issues in nursing. New York, NY: Elsevier Health Sciences.

Creswell, J. W. (2009). Research design: Qualitative, quantitative, and mixed methods approaches (3rd ed.). Thousand Oaks, CA: Sage. 
Empowerment of Home Health Care Case Managers

Dall, T. M., Gallo, P. D., Chakrabarti, R., West, T., Semilla, A. P., \& Storm, M. V. (2013). An aging population and growing disease burden will require a large and specialized health care workforce by 2025 . Health Affairs, 32(11), 2013-2020.doi:10.1377/hlthaff.2013. 0714

Davies, S. L., Goodman, C., Bunn, F., Victor, C., Dickinson, A., Iliffe, S., ... \& Froggatt, K. (2011). A systematic review of integrated working between care homes and health care services. BMC health services research, 11(1), 1. doi: $10.1186 / 1472-6963-11-320$

Ellenbecker, C., Samia, L., Cushman, M., \& Alster, K. (2008). Patient safety and quality in home health care. In R. G. Hughes (Ed.), Patient safety \& quality: An evidence-based handbook for nurses (pp. 1-40). Rockville, MD: Agency for Healthcare Research and Quality.

Harris, M. D. (2015). Handbook of home health care administration. Burlington, MA: Jones \& Bartlett.

Harris-Kojetin, L., Sengupta, M., Park-Lee, E., \& Valverde, R. (2013). Long-term care services in the United States: 2013 overview. Hyattsville, MD: National Center for Health Statistics.

Kanter, R. M. (1993b). Employability security. Business and Society Review, 87, 9-17. Retrieved from http:// onlinelibrary.wiley.com/journal/10.1111/(ISSN)1467-8594

Laschinger, H. K. S. (2008). Effect of empowerment on professional practice environments, work satisfaction, and patient care quality: Further testing the nursing worklife model. Journal of Nursing Care Quality, 23(4), 322-330. doi: 10.1097/01.NCQ.0000318028.67910.6b

Laschinger, H. K. S., Finegan, J., Shamian, J., \& Wilk, P. (2001). Impact of structural and psychological empowerment on job strain in nursing work settings: Expanding Kanter's model. Journal of Nursing Administration, 31(5), 260-272. Retrieved from http://journals.lww.com/jonajournal/Pages/default.aspx

Manojlovich, M. (2007). Power and empowerment in nursing: Looking backward to inform the future. OJIN:The Online Journal of Issues in Nursing, 12(1), 1. Retrieved from http://www.nursingworld.org/OJIN

Rao, A. (2012). The contemporary construction of nurse empowerment. Journal of Nursing Scholarship, 44(4), 396-402.doi:10.1111/j.1547-5069.2012.01473.x

Trus, M., Razbadauskas, A., Doran, D., \& Suominen, T. (2012). Work-related empowerment of nurse managers: A systematic review. Nursing \& Health Sciences, 14(3), 412-420.doi:10.1111/j.1442-2018.2012.00694.x

Williamson, K. M. (2007). Home health care nurses' perceptions of empowerment. Journal of Community Health Nursing, 24(3), 133-153.http://dx.doi.org/10.1080/07370010701429512

Visiting Nurse Associations of America (2015) VNAA Manual of Hospice and Palliative Care. Retrieved from http://www.vnaa.org/

Wong, C. A., \& Laschinger, H. K. (2013). Authentic leadership, performance, and job satisfaction: the mediating role of empowerment. Journal of advanced nursing, 69(4), 947-959. doi: 10.1111/j.1365-2648.2012.06089.x

Citation: Linda Basso Melodia, Barbara Penprase, Linda L. Strong "Empowerment of Home Health Care Case Managers". American Research Journal of Nursing. 2017;3(1):1-7.

Copyright (c) 2017 FLinda Basso Melodia, Barbara Penprase, Linda L. Strong, This is an open access article distributed under the Creative Commons Attribution License, which permits unrestricted use, distribution, and reproduction in any medium, provided the original work is properly cited. 